\title{
PERTINENCIA EDITORIAL DE LAS REVISTAS CIENTÍFICAS DE LA UNIVERSIDAD SANTO TOMÁS DE BOGOTÁ, diciembre de 2014
}

\section{Una revista científica}

Las revistas científicas poseen, además de las características que son comunes a todas las revistas, una clara y conocida estructura administrativa, que corresponde al comité editorial, al editor y su equipo, y al comité científico y su equivalente, de igual manera, tiene una periodicidad declarada y respetada que evidencia el alcance y pertinencia de la publicación a nivel nacional e internacional.

Son criterios indispensables para la clasificación de una revista la calidad científica, calidad editorial, estabilidad $\mathrm{y}$ en gran medida la visibilidad y reconocimiento nacional e internacional.

\section{Calidad científica}

De acuerdo a Publindex, la calidad científica se mide por la tipología de los documentos publicados, siendo los reportes originales de investigación (artículos de investigación científica y tecnológica), los análisis críticos de temas con base en resultados

originales de investigación (artículos de reflexión) y las revisiones de la literatura con más de cincuenta referencias (artículos de revisión), los que más peso tienen en la evaluación.

Para ISI y SCOPUS es más valiosa la publicación de resultados científicos provenientes de un trabajo de investigación riguroso y serio en un tema especializado, debido a que la investigación científica da origen a campos especializados de estudio que logran nuevos temas y generan mayor alcance. Un artículo de investigación bien estructurado, con una metodología definida proporciona un análisis de resultados capaz de dar origen a nuevas investigaciones.

\section{Calidad editorial}

Para la calidad editorial Publindex verifica que la revista integre las normas editoriales que caracterizan a las publicaciones seriadas en el campo de la ciencia y la tecnología. Dentro de sus exigencias editoriales esta la construcción de resúmenes sólidos que den cuenta del planteamiento esencial del artículo.

SCOPUS e ISI revisan si la revista cumple o no los requisitos editoriales internacionales. Estos requisitos incluyen títulos de revistas informativos, títulos de artículos y resúmenes (en inglés principalmente) completamente descriptivos, datos bibliográficos completos en todas las referencias citadas, e información completa sobre la dirección para cada autor.

SCOPUS hace énfasis en la política editorial de la revista, y se asegura que el contenido de la publicación haya pasado por un arbitraje doble ciego, y tenga una descripción a disposición del público del proceso de revisión por pares. Adicionalmente, revisa que la 
revista tenga una declaración de buenas prácticas que evite el plagio y la publicación de ciencia irrelevante.

\section{Estabilidad}

La estabilidad se verifica con el cumplimiento en las fechas de publicación según su periodicidad, lo que evidencia a su vez la antigüedad en el medio.

SCOPUS e ISI son mucho más exigente en este aspecto y no conciben que un título salga a publicación semanas o meses después de la fecha que aparece en su portada, y mucho menos que este suceso se haga habitual. Para medir debidamente este aspecto del cumplimiento de la periodicidad realizan la evaluación de al menos tres números diferentes de la revista que se trate.

\section{La visibilidad y reconocimiento nacional e internacional}

Para Publindex los elementos asociados a este criterio de clasificación son los niveles de circulación y de accesibilidad de la revista, las formas y niveles de distribución, la integración en las bases bibliográficas secundarias nacionales e internacionales, y la existencia de colecciones completas en la Biblioteca Nacional, la Biblioteca Central de la Universidad Nacional de Colombia, la Biblioteca del Congreso y en bibliotecas departamentales.

EI ISI trata de indizar las revistas con diversidad internacional entre los autores y comités, tanto de los artículos originales, como de los artículos citados, con el objetivo de satisfacer las necesidades de su base de suscriptores internacionales. De igual forma el ISI indexa las mejores revistas regionales para reflejar apropiadamente el contexto global en el cual tiene lugar la investigación científica y, para proporcionar cobertura balanceada en cada categoría. 


\section{Condiciones para la clasificación de revistas en el índice bibliográfico nacional Publindex, SCOPUS y el Institute for Scientific Information (ISI)}

\section{PUBLINDEX}

\begin{tabular}{|c|c|c|c|c|}
\hline Calidad & Categoría A1 & Categoría A2 & Categoría B & Categoría C \\
\hline Científica & $\begin{array}{l}\text { Para que una revista } \\
\text { sea indexada en la } \\
\text { categoría A1 debe } \\
\text { cumplir las condiciones } \\
\text { para la categoría A2 y } \\
\text { adicionalmente las } \\
\text { siguientes: } \\
\text { Pertenecer a más de un } \\
\text { índice bibliográfico } \\
\text { durante el periodo de } \\
\text { observación. } \\
\text { Pertenecer a más de un } \\
\text { índice bibliográfico } \\
\text { durante el periodo de } \\
\text { observación. } \\
\text { Tener una periodicidad } \\
\text { mínima semestral y las } \\
\text { que sean establecidas } \\
\text { por el Comité Científico } \\
\text { del Índice. }\end{array}$ & 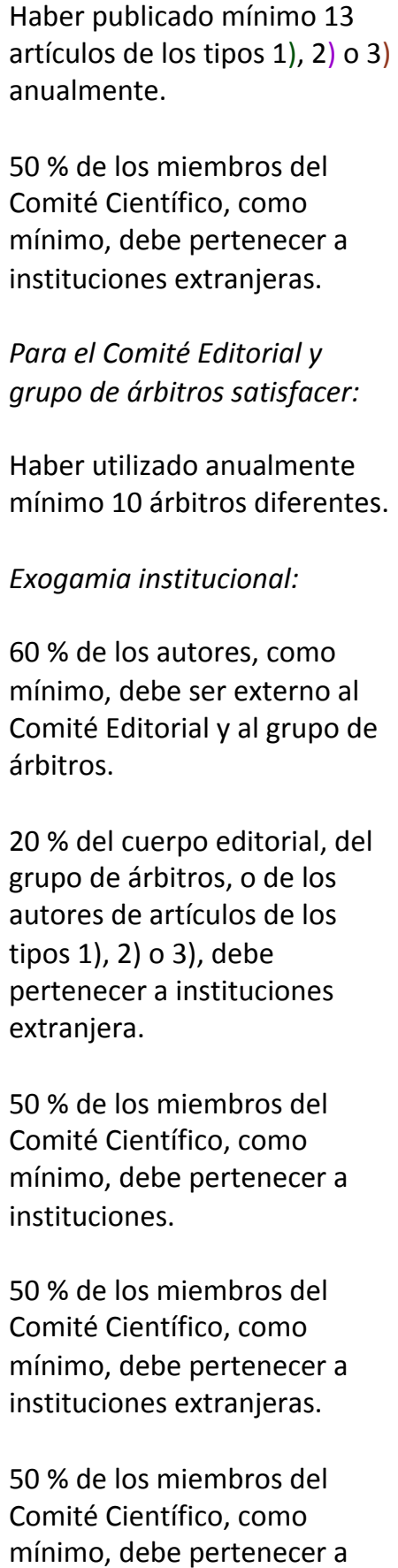 & $\begin{array}{l}\text { Haber publicado mínimo } 11 \\
\text { artículos de los tipos 1), 2) } \\
\text { o } 3 \text { ) anualmente. } \\
\text { Para el Comité Editorial y } \\
\text { grupo de árbitros, } \\
\text { satisfacer al menos cuatro } \\
\text { de las siete condiciones } \\
\text { siguientes: } \\
\text { 50 \% de los miembros del } \\
\text { Comité Editorial debe tener } \\
\text { título de doctorado. } \\
\text { 50\% de los miembros del } \\
\text { Comité Editorial debe ser } \\
\text { externo a la institución } \\
\text { editora. } \\
\text { ser externo a la institución } \\
\text { editora y diferente de los } \\
\text { miembros del Comité } \\
\text { 50 \% de los miembros del } \\
\text { Comité Editorial debe ser } \\
\text { externo a la institución } \\
\text { editora. } \\
\text { anaber utilizado mínimo } 8 \\
\text { Cada uno de los miembros } \\
\text { del Comité Editorial debe } \\
\text { haber publicado en los dos } \\
\text { años anteriores al periodo } \\
\text { de observación al menos } \\
\text { un artículo del tipo 1), } 2 \text { ), } 3 \text { ) } \\
\text { en otras revistas arbitradas } \\
\text { afines a la cobertura } \\
\text { temática de la revista. } \\
\text { ante. }\end{array}$ & $\begin{array}{l}\text { Haber publicado } \\
\text { mínimo } 9 \text { artículos de } \\
\text { los tipos 1), 2) o 3) } \\
\text { anualmente. } \\
\text { Haber utilizado } \\
\text { mínimo } 7 \text { árbitros } \\
\text { diferentes } \\
\text { anualmente. }\end{array}$ \\
\hline
\end{tabular}




\begin{tabular}{|c|c|c|c|}
\hline - & & $\begin{array}{l}\text { instituciones extranjeras. } \\
50 \% \text { de los miembros del } \\
\text { Comité Científico debe haber } \\
\text { publicado durante los dos años } \\
\text { anteriores en revistas } \\
\text { indexadas internacionalmente. }\end{array}$ & \begin{tabular}{|l|} 
Editorial. \\
$30 \%$ del grupo de árbitros \\
utilizados durante el \\
periodo de observación \\
debe tener nivel de \\
maestría. \\
Cada uno de los árbitros \\
debe haber debe haber \\
publicado en los dos años \\
anteriores al periodo de \\
observación al menos un \\
artículo del tipo 1), 2), 3) en \\
otras revistas arbitradas \\
afines a la cobertura \\
temática de la revista. \\
Para Autores, satisfacer al \\
menos una de las \\
siguientes condiciones: \\
60\% de los autores de los \\
documentos tipos 1), 2) o \\
3) debe ser diferente de los \\
miembros del Comité \\
Editorial y del grupo de \\
árbitros. \\
$30 \%$ de los autores de los \\
documentos tipos 1), 2) o \\
3) debe ser externo a la \\
institución editora de la \\
revista.
\end{tabular} \\
\hline
\end{tabular}

\begin{tabular}{|c|c|c|c|c|}
\hline Calidad & $\begin{array}{c}\text { Categorí } \\
\text { a A1 }\end{array}$ & Categoría A2 & Categoría B & Categoría C \\
\hline
\end{tabular}




\begin{tabular}{|c|c|c|c|}
\hline Editorial & $\begin{array}{l}\text { Tener resumen analítico en } \\
\text { dos idiomas en cada uno de } \\
\text { los documentos de los tipos } \\
\text { 1), 2), o 3). } \\
\text { Tener palabras clave en cada } \\
\text { uno de los documentos de los } \\
\text { tipos 1), 2), 3). } \\
\text { Tener URL para el caso de las } \\
\text { revistas electrónicas. } \\
\text { Cumplir una de las dos } \\
\text { condiciones siguientes: } \\
\text { Presentar información para } \\
\text { obtener y reproducir los } \\
\text { documentos publicados. } \\
\text { Presentar índices periódicos } \\
\text { por volumen. }\end{array}$ & $\begin{array}{l}\text { Presentar leyenda bibliográfica en } \\
\text { la portada de cada revista. } \\
\text { Tener resumen en al menos dos } \\
\text { idiomas en el } 75 \% \text { de los } \\
\text { documentos tipos 1), 2), 3). } \\
\text { Tener leyenda bibliográfica en la } \\
\text { página inicial de cada artículo. } \\
\text { Presentar fecha de recepción y } \\
\text { aceptación en todos los } \\
\text { documentos de los tipos 1), 2), 3). } \\
\text { Tener instrucciones explícitas, } \\
\text { dirigidas a los autores, para la } \\
\text { presentación de los documentos. } \\
\text { Tener hipervínculos a autores, } \\
\text { referencias bibliográficas y gráficos } \\
\text { para el caso de las revistas } \\
\text { electrónicas. } \\
\text { Describir al público al que se } \\
\text { dirige. }\end{array}$ & $\begin{array}{l}\text { Mencionar la entidad editora. } \\
\text { Tener dirección postal en cada } \\
\text { uno de los fascículos. } \\
\text { Tener tabla de contenido en } \\
\text { cada uno de los fascículos. } \\
\text { Declarar la afiliación institucional } \\
\text { de los autores en el } 60 \% \text { de los } \\
\text { documentos de los tipos } 1), 2 \text { ), o } \\
\text { 3). } \\
\text { Tener numeración en cada uno } \\
\text { de los fascículos. }\end{array}$ \\
\hline
\end{tabular}

\begin{tabular}{|c|l|l|l|l|}
\hline Calidad & $\begin{array}{c}\text { Categorí } \\
\text { a A1 }\end{array}$ & \multicolumn{1}{|c|}{ Categoría A2 } & \multicolumn{1}{|c|}{ Categoría B } & \multicolumn{1}{|c|}{ Categoría C } \\
\hline $\begin{array}{c}\text { Estabilida } \\
\text { d }\end{array}$ & $\begin{array}{l}\text { Cumplir con las fechas de } \\
\text { publicación según la } \\
\text { periodicidad declarada. }\end{array}$ & $\begin{array}{l}\text { Cumplir con las fechas de } \\
\text { publicación según la periodicidad } \\
\text { declarada. } \\
\text { Tener mínimo tres años de } \\
\text { existencia. } \\
\text { Para las revistas electrónicas, } \\
\text { presentar registro de visitantes. } \\
\text { Tener canje con 10 revistas. }\end{array}$ & $\begin{array}{l}\text { Cumplir con las fechas de } \\
\text { publicán según la } \\
\text { periodicidad declarada. } \\
\text { Tener como mínimo dos años } \\
\text { de existencia. }\end{array}$ \\
& $\begin{array}{l}\text { Tener 20 o más suscriptores. } \\
\text { Estar integrada en bases } \\
\text { bibliográficas con comité científico } \\
\text { de selección afines a la cobertura } \\
\text { temática de la revista durante el } \\
\text { periodo de observación, que están } \\
\text { incluidas en el documento 'sistemas } \\
\text { de indexación y resumen' publicado } \\
\text { en la página de Publindex. }\end{array}$ & \\
\hline
\end{tabular}




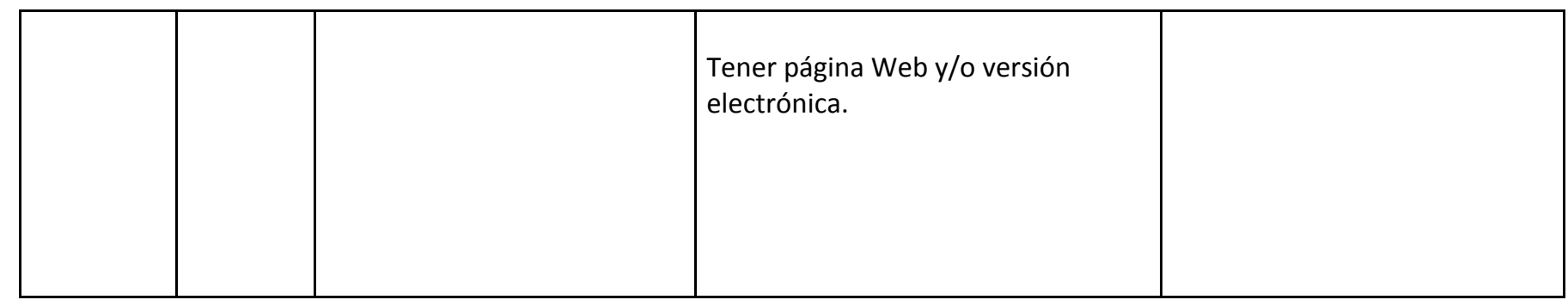

\begin{tabular}{|c|c|c|c|c|}
\hline Categoría & Categoría A1 & Categoría A2 & Categoría B & Categoría C \\
\hline $\begin{array}{c}\text { Visibilida } \\
\text { d }\end{array}$ & & $\begin{array}{l}\text { Estar indexada en al menos un (1) índice bibliográfico durante el } \\
\text { periodo de observación, ó en tres (3) bases bibliográficas con comité } \\
\text { científico de selección, que están incluidas en el documento } \\
\text { 'sistemas de indexación y resumen' publicado en la página de } \\
\text { Publindex. } \\
\text { Tener más de } 40 \text { suscriptores. }\end{array}$ & & \\
\hline
\end{tabular}

\section{SCOPUS}

\begin{tabular}{|c|c|c|}
\hline Categoría & Criterios & Evaluación \\
\hline \multirow[b]{3}{*}{ Política de Diario } & Tipo de evaluación por pares & \multirow{3}{*}{$35 \%$} \\
\hline & Diversidad en la distribución geográfica del equipo editorial & \\
\hline & Diversidad de los autores (instituciones, geografía...) & \\
\hline \multirow[b]{2}{*}{ Contenido } & Calidad y conformidad con los objetivos declarados y el alcance de la revista & \multirow{2}{*}{$20 \%$} \\
\hline & Claridad de los artículos: estructura, compresión... & \\
\hline Diario Permanente & Citas a los artículos de la revista reflejadas en Scopus & $25 \%$ \\
\hline \multirow[b]{2}{*}{ Disponibilidad en línea } & Al menos la página principal de la web debe estar disponible en inglés & \multirow[t]{2}{*}{$10 \%$} \\
\hline & Calidad de la página: diseño, navegabilidad, servicios añadidos... & \\
\hline
\end{tabular}


ISI

\begin{tabular}{|l|l|}
\hline \multicolumn{2}{|l|}{ Criterios } \\
\hline Patrones básicos para \\
revistas & $\begin{array}{l}\text { Periodicidad. La habilidad para publicar a tiempo implica contar con una reserva sustancial de } \\
\text { manuscritos que garanticen las salidas puntuales de la revista. } \\
\text { Requisitos editoriales internacionales. Estos requisitos incluyen títulos de revistas informativos, } \\
\text { títulos de artículos y resúmenes completamente descriptivos, datos bibliográficos completos en } \\
\text { todas las referencias citadas, e información completa sobre la dirección para cada autor. Títulos } \\
\text { de los artículos en inglés, los resúmenes, y las palabras claves. }\end{array}$ \\
\hline Contenido editorial & $\begin{array}{l}\text { El contenido de una nueva revista enriquecerá la base de datos o si el tema ya está } \\
\text { adecuadamente cubierto. }\end{array}$ \\
\hline Internacionalidad & $\begin{array}{l}\text { Revistas con diversidad internacional entre los autores, tanto de los artículos originales, como de } \\
\text { los artículos citados. } \\
\text { Mejores revistas regionales }\end{array}$ \\
\hline Análisis de citas & $\begin{array}{l}\text { Para las revistas establecidas, se revisan citas completas, factor de impacto, e índice de } \\
\text { inmediatez. Para las revistas recién creadas, se examina el registro de publicaciones de los } \\
\text { autores y de los miembros del cuerpo editorial, para conocer dónde se han publicado sus } \\
\text { artículos y si sus trabajos se han citado. }\end{array}$ \\
\hline
\end{tabular}

\section{Análisis llevado a cabo con las revistas científicas de la USTA}

Los criterios utilizados para el análisis fueron:

1. Nivel de endogamia en autores, pares evaluadores, comités editoriales y científicos.

2. Periodicidad.

3. Pertinencia y competencia temática en el área de conocimiento afín a su contenido.

4. Nivel de indexación.

5. Estructura editorial (apoyo real de la unidad o de la facultad al proyecto editorial de publicación periódica científica).

A partir de esta información se han dividido las publicaciones en tres grupos así:

Grupo 1. Publicaciones que cumplen con los cinco criterios: 


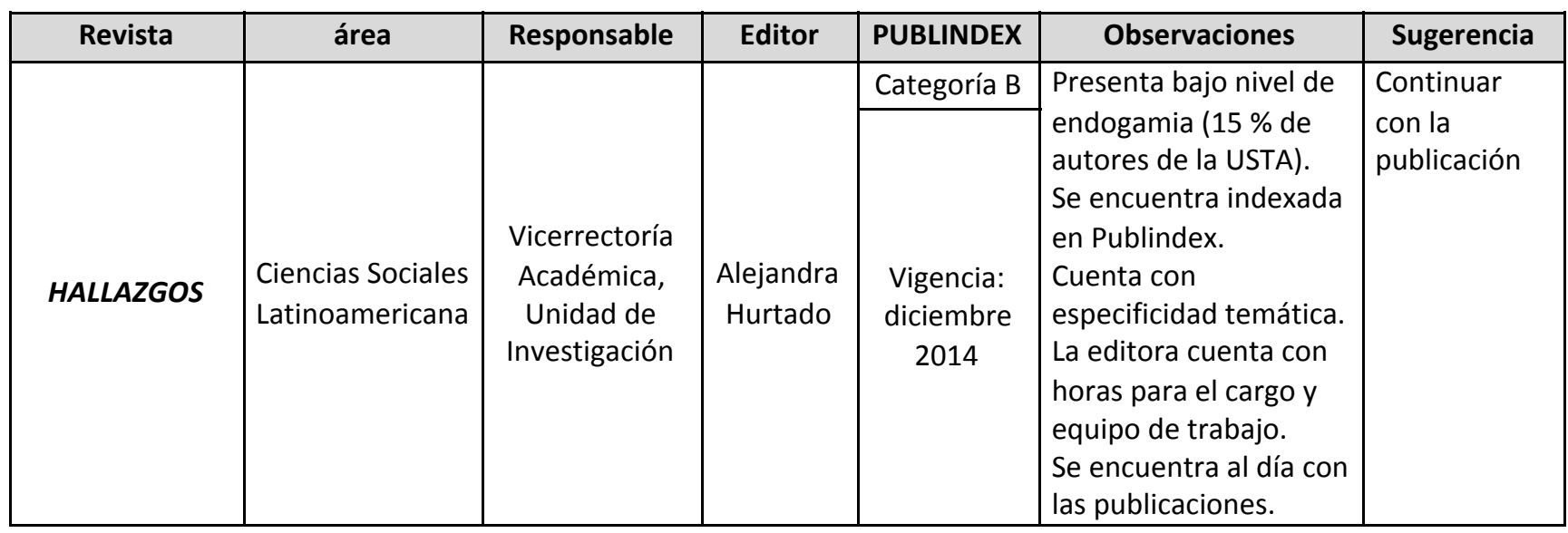

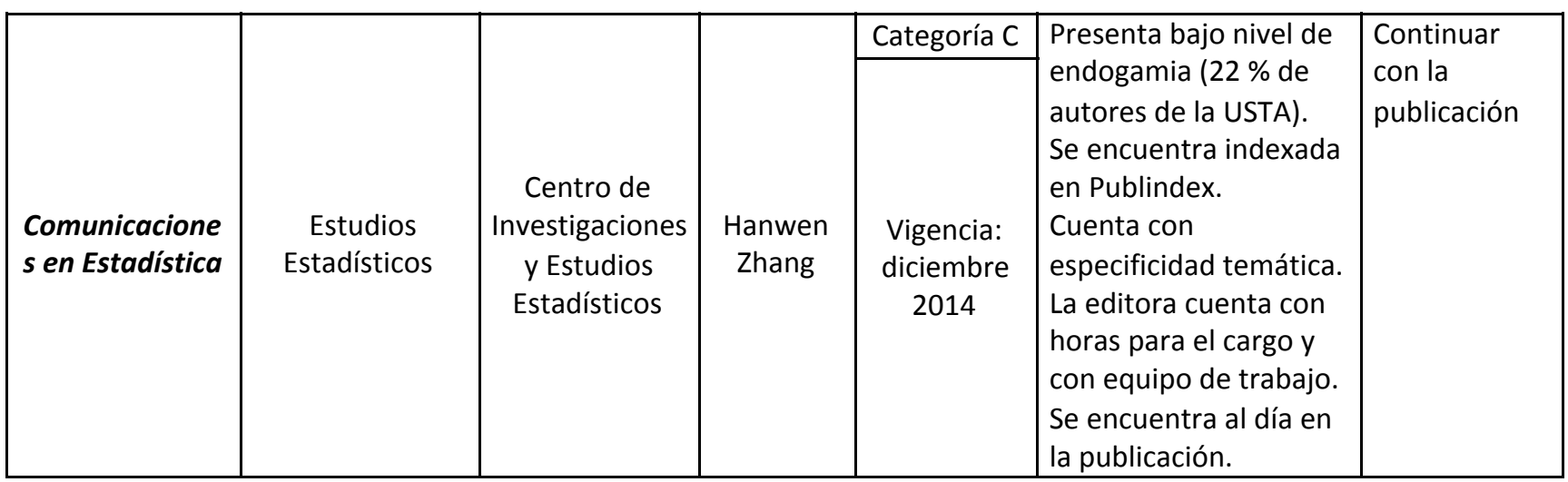

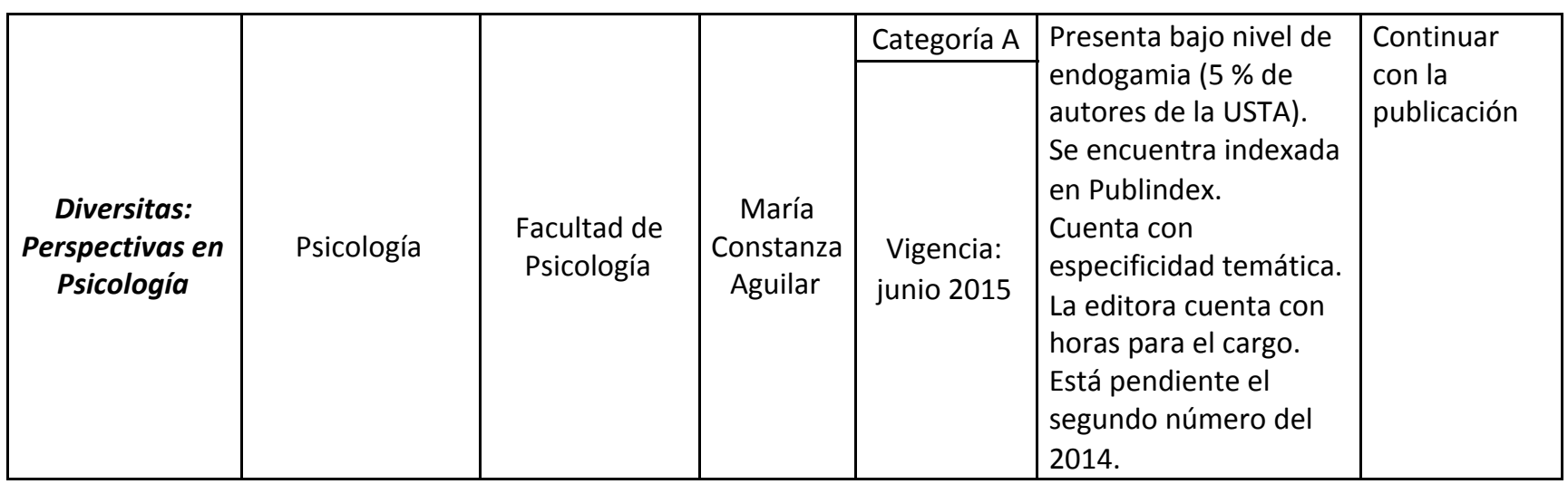

Grupo 2. No cumplen con todos los cinco criterios pero que, de acuerdo a las condiciones del mercado, según su área y posibilidades de indexación se puede mantener con el cumplimiento de algunos compromisos. Dentro de este grupo también se encuentran las publicaciones que pueden ser fusionadas con otras de la misma área de la USTA: 


\begin{tabular}{|c|c|c|c|c|c|c|}
\hline Revista & área & Responsable & Editor & PUBLINDEX & Observaciones & Sugerencia \\
\hline Albertus Magnus & Teología & $\begin{array}{c}\text { Facultad de } \\
\text { Teología }\end{array}$ & 要 & & $\begin{array}{l}\text { Aunque presenta alto } \\
\text { nivel de endogamia (62 } \\
\% \text { de autores son de la } \\
\text { USTA), en el primer } \\
\text { número del } 2014 \text { se } \\
\text { han hecho las } \\
\text { correcciones necesarias } \\
\text { y se ha bajado de } \\
\text { manera significativa la } \\
\text { endogamia (14,2 \% de } \\
\text { autores de la USTA). } \\
\text { No se encuentra } \\
\text { indexada pero es muy } \\
\text { posible su indexación ya } \\
\text { que cumple con los } \\
\text { requisitos y hay pocas } \\
\text { revistas de la misma } \\
\text { temática (1 revista en } \\
\text { Publindex categoría C ). } \\
\text { El editor cuenta con } \\
\text { horas para el cargo y } \\
\text { tiene equipo editorial } \\
\text { con la capacidad de } \\
\text { formar redes de trabajo } \\
\text { que le permiten } \\
\text { fortalecer el contenido } \\
\text { de la publicación. } \\
\text { Está en proceso de } \\
\text { quedar al día con los } \\
\text { dos números de } 2014 \\
\text { (en edición). }\end{array}$ & $\begin{array}{l}\text { Mantener y } \\
\text { mejorar el } \\
\text { plan para } \\
\text { solidificar la } \\
\text { revista y su } \\
\text { indexación } \\
\text { en un plazo } \\
\text { de dos años. }\end{array}$ \\
\hline
\end{tabular}

\begin{tabular}{|c|c|c|c|c|c|c|}
\hline $\begin{array}{l}\text { Cuadernos de } \\
\text { Filosofía } \\
\text { Latinoamericana }\end{array}$ & $\begin{array}{c}\text { Filosofía } \\
\text { Latinoamericana }\end{array}$ & $\begin{array}{c}\text { Facultad de } \\
\text { Filosofía y } \\
\text { Letras }\end{array}$ & $\begin{array}{l}\text { César } \\
\text { Fredy } \\
\text { Pongutá }\end{array}$ & Categoría C & $\begin{array}{l}\text { Presenta alto nivel de } \\
\text { endogamia ( } 42 \% \text { de } \\
\text { autores de la USTA) } \\
\text { Es una revista de } \\
\text { reconocida trayectoria, } \\
\text { cuenta con } \\
\text { especificidad temática. } \\
\text { Se encuentra indexada } \\
\text { en Pubindex. } \\
\text { El editor cuenta horas } \\
\text { para su cargo pero no } \\
\text { tiene horas para } \\
\text { asistencia a comités de } \\
\text { editores de revistas } \\
\text { científicas. } \\
\text { La revista se encuentra } \\
\text { atrasada con los } \\
\text { números del 2014, pero } \\
\text { existe un compromiso }\end{array}$ & $\begin{array}{l}\text { Continuar } \\
\text { con la } \\
\text { publicación } \\
\text { siempre y } \\
\text { cuando se } \\
\text { pongan al día } \\
\text { con la } \\
\text { periodicidad } \\
\text { y se } \\
\text { mantenga. }\end{array}$ \\
\hline
\end{tabular}




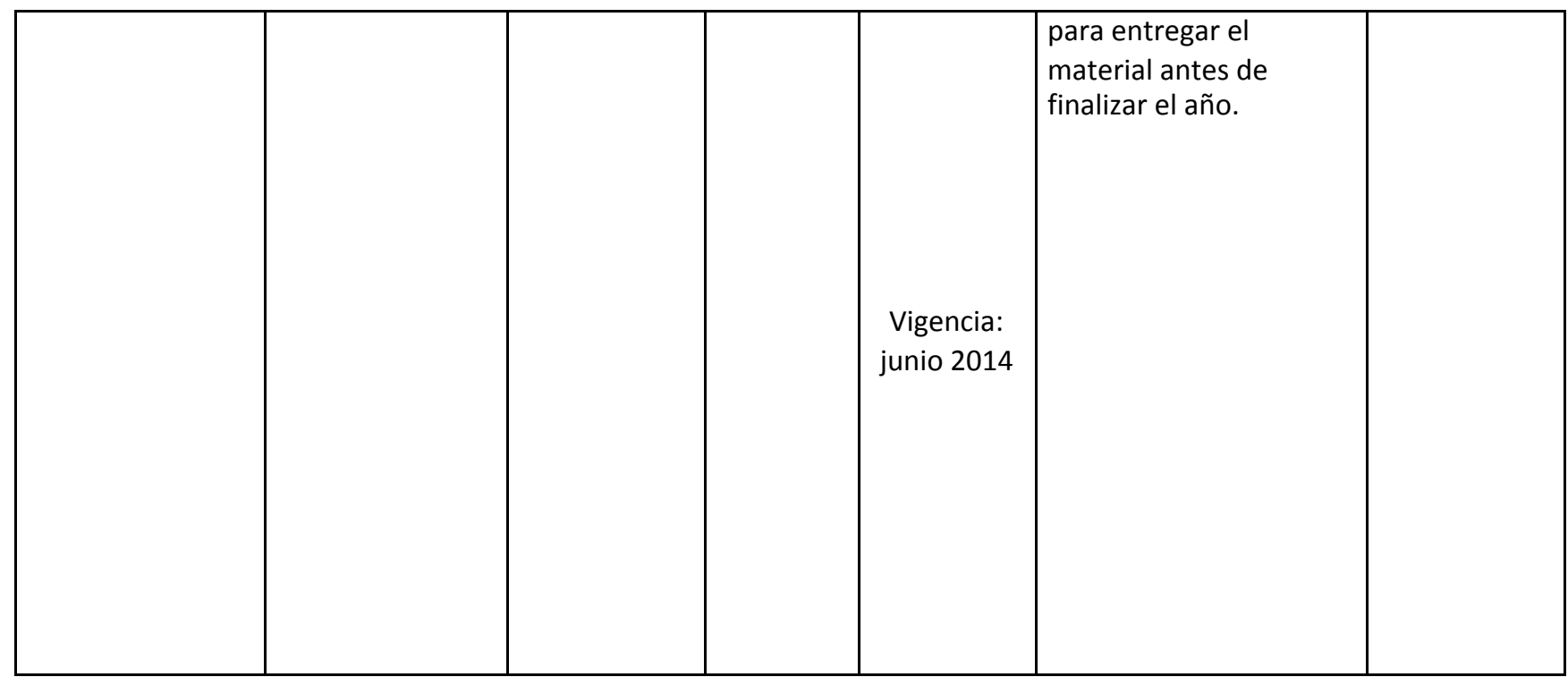

\begin{tabular}{|c|c|c|c|c|c|}
\hline $\begin{array}{c}\text { Cuerpo Cultura y } \\
\text { Movimiento }\end{array}$ & $\begin{array}{c}\text { Cultura Física, } \\
\text { Deporte y } \\
\text { Recreación }\end{array}$ & $\begin{array}{l}\text { Facultad de } \\
\text { Cultura } \\
\text { Física, } \\
\text { Deporte y } \\
\text { Recreación }\end{array}$ & $\begin{array}{l}\text { Carmen } \\
\text { Victoria } \\
\text { Forero }\end{array}$ & $\begin{array}{l}\text { Presenta alto nivel de } \\
\text { endogamia ( } 50 \% \text { de } \\
\text { autores de la USTA) } \\
\text { No se encuentra } \\
\text { indexada. } \\
\text { La editora cuenta con } \\
\text { horas para el cargo y } \\
\text { con equipo de trabajo. } \\
\text { La publicación está } \\
\text { atrasada tres números } \\
\text { pero existe un } \\
\text { compromiso para la } \\
\text { entrega del material al } \\
\text { final del semestre. }\end{array}$ & $\begin{array}{l}\text { Sugiere } \\
\text { ponerse al } \\
\text { día, } \\
\text { mantener su } \\
\text { periodicidad } \\
\text { y presentarse } \\
\text { a Publindex } \\
\text { en un plazo } \\
\text { de dos años } \\
\text { ya que hay } \\
\text { pocas } \\
\text { revistas de la } \\
\text { misma } \\
\text { temática. }\end{array}$ \\
\hline
\end{tabular}

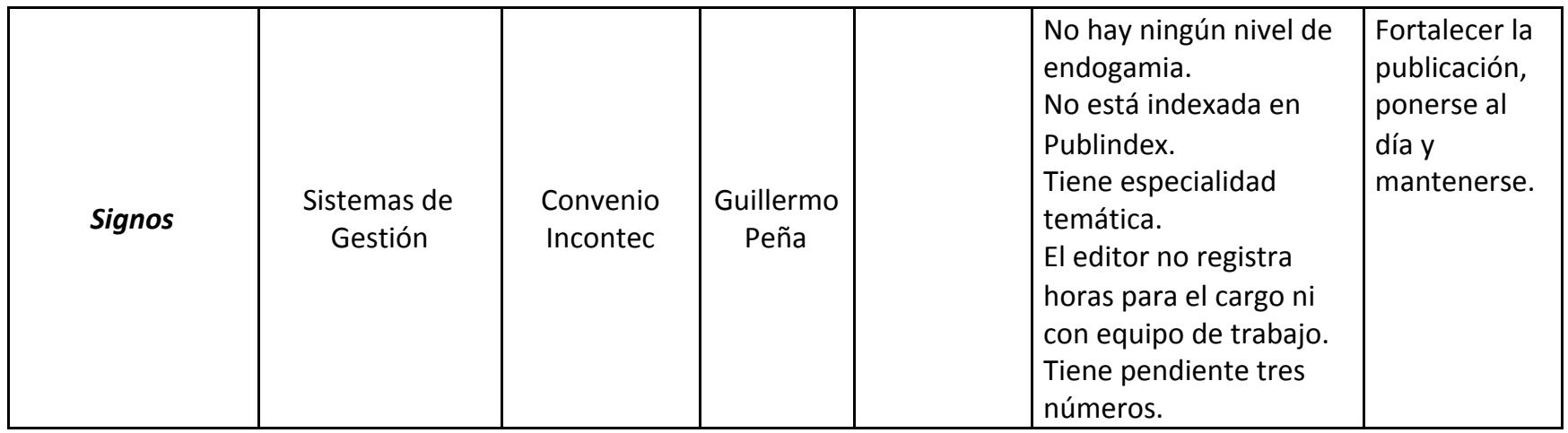

Posibles fusiones 


\begin{tabular}{|c|c|c|c|c|c|c|}
\hline Revista & área & Responsable & Editor & PUBLINDEX & Observaciones & Sugerencia \\
\hline CIFE & Economía & $\begin{array}{l}\text { Centro de } \\
\text { Investigaciones } \\
\text { Facultad de } \\
\text { Economía }\end{array}$ & $\begin{array}{c}\text { Jorge E. } \\
\text { Martínez } \\
\text { Carvajal }\end{array}$ & & $\begin{array}{l}\text { Presenta alto nivel de } \\
\text { endogamia ( } 50 \% \text { de autores de } \\
\text { la USTA). } \\
\text { Se presentó recientemente a } \\
\text { Publindex y no fue indexada. } \\
\text { No cuenta con especificidad } \\
\text { temática dentro de esta gran } \\
\text { área del conocimiento en la cual } \\
\text { existen gran cantidad de revistas } \\
\text { de la misma área. } \\
\text { El editor actual no cuenta con } \\
\text { horas para el cargo ya que tiene } \\
\text { dos meses de estar en este } \\
\text { cargo. } \\
\text { Cuenta con equipo de trabajo. } \\
\text { Se encuentra atrasada la } \\
\text { publicación en los dos números } \\
\text { del } 2014, \text { existe un compromiso } \\
\text { para entregar el nuevo material } \\
\text { a final de semestre. }\end{array}$ & $\begin{array}{l}\text { Existe la revista } \\
\text { Lebret de la misma } \\
\text { área en } \\
\text { Bucaramanga, } \\
\text { categoría C en } \\
\text { Publindex. Se } \\
\text { sugiere suspender } \\
\text { su publicación o ver } \\
\text { la viabilidad de la } \\
\text { fusión con la revista } \\
\text { de Bucaramanga. }\end{array}$ \\
\hline
\end{tabular}

\begin{tabular}{|c|c|c|c|c|c|c|}
\hline & & & & Categoría C & Presenta alto nivel de & \\
\hline IUSTA & Derecho & $\begin{array}{c}\text { Facultad de } \\
\text { Derecho }\end{array}$ & $\begin{array}{c}\text { Ricardo } \\
\text { Palomares }\end{array}$ & $\begin{array}{c}\text { Vigencia: } \\
\text { junio } 2014\end{array}$ & $\begin{array}{l}\text { la USTA) aunque en el último } \\
\text { número bajó ese nivel de } \\
\text { manera significativa ( } 16,6 \% \text { de } \\
\text { autores de la USTA). } \\
\text { Se encuentra en proceso de } \\
\text { evaluación en Publindex. } \\
\text { El editor cuenta con horas para } \\
\text { el cargo pero es editor de dos } \\
\text { publicaciones y secretario del } \\
\text { Comité Editorial de División. } \\
\text { No tiene equipo de trabajo. } \\
\text { Se encuentra atrasada con el } \\
\text { segundo número del } 2014 .\end{array}$ & $\begin{array}{l}\text { con la periodicidad. } \\
\text { De igual manera que } \\
\text { el editor solo dirija } \\
\text { una revista. }\end{array}$ \\
\hline
\end{tabular}

\begin{tabular}{|c|c|c|c|l|l|}
\hline $\begin{array}{c}\text { Viet } \\
\begin{array}{c}\text { Inveniendi } \\
\text { et ludicandi } \\
\text { (Virtual) }\end{array}\end{array}$ & Derecho & $\begin{array}{c}\text { Facultad de } \\
\text { Derecho }\end{array}$ & $\begin{array}{c}\text { Ricardo } \\
\text { Palomares }\end{array}$ & $\begin{array}{l}\text { Categoría C } \\
\text { Vigencia: } \\
\text { junio } 2015\end{array}$ & $\begin{array}{l}\text { Presenta nivel medio de } \\
\text { endogamia (33\% de autores de } \\
\text { la USTA). } \\
\text { Se encuentra indexada en } \\
\text { Publindex. } \\
\text { El editor cuenta con horas para } \\
\text { el cargo pero es editor de dos } \\
\text { publicaciones y secretario del }\end{array}$ \\
\hline
\end{tabular}




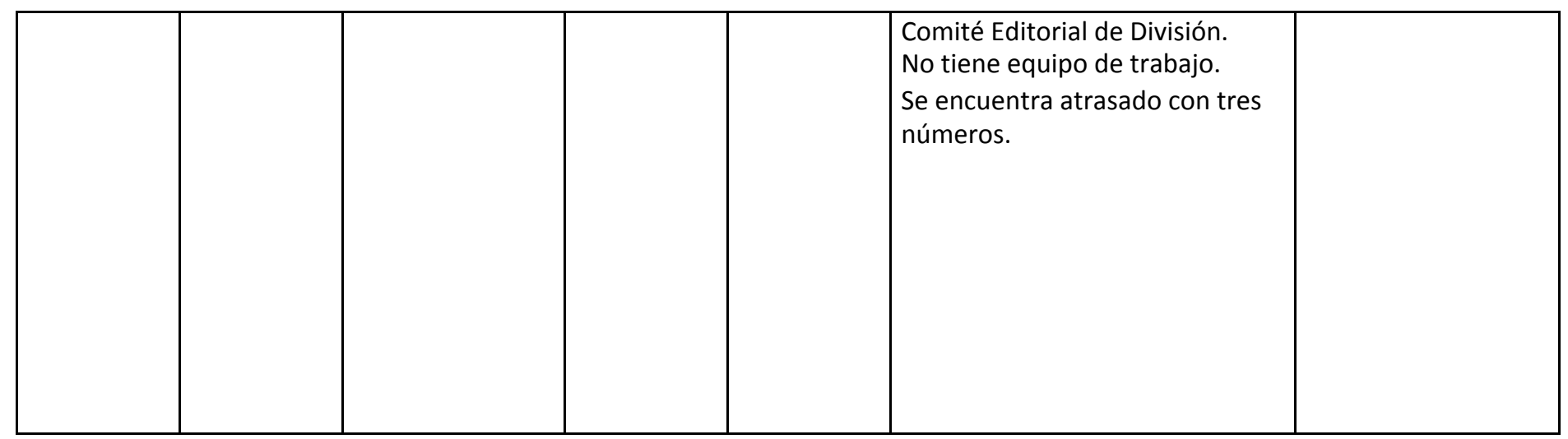

\begin{tabular}{|c|c|c|c|c|c|c|}
\hline & & & & Categoría C & Presenta bajo nivel de & Fusionar con la \\
\hline Magistro & Educación & $\begin{array}{l}\text { Maestría en } \\
\text { Educación - } \\
\text { VUAD }\end{array}$ & $\begin{array}{l}\text { José Luis } \\
\text { Jiménez } \mathrm{H} \text {. }\end{array}$ & $\begin{array}{l}\text { Vigencia: } \\
\text { junio } 2014\end{array}$ & $\begin{array}{l}\text { la USTA). } \\
\text { Está indexada en Publindex. } \\
\text { No tiene especialidad temática. } \\
\text { El editor no cuenta con tiempo } \\
\text { para el cargo ni con equipo de } \\
\text { trabajo. } \\
\text { Tiene pendiente el segundo } \\
\text { número del } 2014 .\end{array}$ & \\
\hline
\end{tabular}

\begin{tabular}{|c|c|c|c|c|c|c|}
\hline RIIEP & Educación & $\begin{array}{l}\text { Facultad de } \\
\text { Educación, } \\
\text { Doctorado en } \\
\text { Educación - } \\
\text { VUAD }\end{array}$ & $\begin{array}{l}\text { José Arlés } \\
\text { Gómez }\end{array}$ & $\begin{array}{c}\text { Categoría C } \\
\text { Vigencia: } \\
\text { junio } 2014\end{array}$ & $\begin{array}{l}\text { Presenta alto nivel de } \\
\text { endogamia ( } 40 \% \text { de autores de } \\
\text { la USTA). } \\
\text { Está indexada en Publindex. } \\
\text { No tiene especialidad temática. } \\
\text { El editor no cuenta con tiempo } \\
\text { para el cargo ni con equipo de } \\
\text { trabajo. } \\
\text { Tiene pendiente el segundo } \\
\text { número del } 2014 .\end{array}$ & $\begin{array}{l}\text { Fusionar con la } \\
\text { revista Magistro. }\end{array}$ \\
\hline
\end{tabular}


Grupo 3. No cumple ninguno de los criterios:

\begin{tabular}{|c|c|c|c|c|c|c|}
\hline Revista & área & Responsable & Editor & PUBLINDEX & Observaciones & Sugerencia \\
\hline Activos & Contabilidad & $\begin{array}{l}\text { Facultad de } \\
\text { Contaduría } \\
\text { Pública }\end{array}$ & $\begin{array}{c}\text { Jairo } \\
\text { Alonso } \\
\text { Bautista }\end{array}$ & & $\begin{array}{l}\text { Alto nivel de endogamia (45 } \\
\% \text { de autores son de la } \\
\text { USTA). } \\
\text { No tiene ningún nivel de } \\
\text { indexación (Solo aparece en } \\
\text { directorios). } \\
\text { Estructura editorial } \\
\text { insuficiente (no cuenta con } \\
\text { asistente, no tiene equipo de } \\
\text { trabajo humano ni técnico). } \\
\text { Editor sin horas asignadas. } \\
\text { No cumple con periodicidad. } \\
\text { Tiene tres números } \\
\text { atrasados. } \\
\text { USTA Colombia ya tiene otra } \\
\text { revista en esta área mejor } \\
\text { posicionada IN VESTIGIUM } \\
\text { IRE de Tunja }\end{array}$ & $\begin{array}{l}\text { Suspender la } \\
\text { publicación. }\end{array}$ \\
\hline
\end{tabular}

\begin{tabular}{|c|c|c|c|c|c|c|}
\hline & & & & Categoría C & Presenta alto nivel de & Suspender la \\
\hline Análisis & Humanidades & $\begin{array}{c}\text { Departamento } \\
\text { de } \\
\text { Humanidades }\end{array}$ & $\begin{array}{l}\text { Omar } \\
\text { León }\end{array}$ & $\begin{array}{c}\text { Vigencia: } \\
\text { diciembre } \\
2014\end{array}$ & $\begin{array}{l}\text { de la USTA) } \\
\text { Está en proceso de } \\
\text { evaluación en Publindex en } \\
\text { la segunda evaluación. } \\
\text { Es una revista generalista, no } \\
\text { cuenta con nivel de } \\
\text { especialidad en alguna área } \\
\text { de conocimiento; en los } \\
\text { sistemas de indexación y } \\
\text { resumen hay una gran } \\
\text { cantidad de revistas del } \\
\text { mismo tema. } \\
\text { El editor cuenta con horas } \\
\text { para su cargo y equipo de } \\
\text { trabajo. } \\
\text { La revista se encuentra } \\
\text { atrasada con los dos } \\
\text { números del } 2014 .\end{array}$ & \\
\hline
\end{tabular}




\begin{tabular}{|c|c|c|c|c|c|}
\hline Campos & $\begin{array}{l}\text { Ciencias } \\
\text { Sociales }\end{array}$ & $\begin{array}{c}\text { División de } \\
\text { Ciencias } \\
\text { Sociales }\end{array}$ & $\begin{array}{c}\text { Juan } \\
\text { Guillermo } \\
\text { Arias }\end{array}$ & $\begin{array}{l}\text { Presenta alto nivel de } \\
\text { endogamia (50 \% de autores } \\
\text { de la USTA) } \\
\text { Es una revista generalista, no } \\
\text { cuenta con nivel de } \\
\text { especialidad en alguna área } \\
\text { de conocimiento; en los } \\
\text { sistemas de indexación y } \\
\text { resumen hay una gran } \\
\text { cantidad de revistas del } \\
\text { mismo tema. } \\
\text { No es una publicación } \\
\text { indexada, tampoco está en } \\
\text { índices bibliográficos } \\
\text { El editor cuenta con horas } \\
\text { para su cargo. } \\
\text { Es una revista que con dos } \\
\text { años de formación ya se } \\
\text { encuentra atrasada con los } \\
\text { dos números del } 2014\end{array}$ & $\begin{array}{l}\text { Suspender la } \\
\text { publicación. }\end{array}$ \\
\hline
\end{tabular}

\section{Planes de mejoramiento.}

Grupo 1. Incentivos por su trabajo constante. Objetivo: reforzar alguno de los criterios que cumple positivamente pero que es el menos desarrollado con respecto a los demás.

Grupo 2. Redefinición de orientación editorial a partir de un plan de mejoramiento que incluya la manera en que va a resolver aquellos criterios, de los cinco, que no está cumpliendo. El plan debe estar listo en 3 meses y el periodo para realizar seguimiento al cumplimiento de metas es de dos años.

Grupo 3. Reestructuración de la revista a partir de un plan de mejoramiento que incluya la manera en que va a resolver los cinco criterios. El plan debe estar listo en 3 meses y el periodo para realizar seguimiento al cumplimiento de metas es de dos años.

Para el grupo 2 y 3 se debe también plantear que el plan de mejoramiento puede incluir la supresión o la fusión de la revista para concentrar el esfuerzo en otros proyectos de la facultad o de la unidad.

\section{Propuesta para estructurar el perfil del editor}

Con el objetivo de institucionalizar la figura del editor y de constituir el proceso editorial acorde con: 
- $\quad$ Exigencias de sistemas de indexación y resúmenes nacionales e internacionales

- $\quad$ Conformación de la Coordinación de Revistas Científicas

- Planes editoriales de esta Coordinación a propósito de la reestructuración del Departamento Editorial

- $\quad$ El fortalecimiento de los procesos de investigación que deben seguir los editores

Se considera necesario repensar el perfil de editor de revistas científicas, dado que a la fecha estos han venido asumiendo una carga académica y laboral que ha impedido el desarrollo de las actividades investigativas, necesarias para asegurar el posicionamiento de las revistas en los sistemas de indexación, nacionales e internacionales. Por ejemplo, a los editores se les asigna un número importante de cursos, junto con otras funciones administrativas, propias de cada facultad, lo que va en detrimento del tiempo que ellos necesitan emplear para el normal desarrollo de sus actividades como editores.

En virtud de lo anterior, es necesario que se cumpla con el medio tiempo como editor de una revista científica estipulado en los lineamientos de nómina y, el otro medio tiempo sea dedicado a las siguientes actividades: un proyecto de investigación por año, asistencia al Comité Particular de Editores de Revistas Científicas, dos veces al mes y la docencia de máximo un curso. Esto obedece a que en el medio editorial es pertinente la producción académica e investigativa del editor, lo cual incluye la constante publicación de artículos en otras revistas indexadas afines a la cobertura temática de la que edita y la participación en proyectos investigativos.

A continuación se especifica el perfil y las funciones que desarrollará el editor de revistas científicas, en el medio tiempo dedicado a la revista:

Perfil del Editor:

- Especialista de gran prestigio con vínculos académicos muy fuertes en la disciplina o profesión a la que se dirige la revista, que le permita establecer redes de conocimiento.

- Manejo de un segundo idioma, preferiblemente inglés.

- Destrezas escriturales y lectoras.

- Conocimiento de los procesos editoriales (corrección de estilo, diagramación, maquetación, etc.).

- Conocimientos sobre el mundo editorial, tanto de los procesos como de las publicaciones "competidoras" nacionales e internacionales.

- Dominio básico de las tecnologías de la información.

- Conocimiento de los principales sistemas de indexación y resumen.

- Conocimiento de los procesos de indexación.

- Trayectoria investigativa: pertenecer a un grupo de investigación y haber participado en algún proyecto investigativo.

- Publicaciones: haber publicado dos artículos en los últimos dos años en revistas indexadas 
Son funciones del Editor, las siguientes:

- Dirigir la revista.

- Representar oficial y legalmente la publicación.

- Gestionar diariamente la publicación, conocer los manuscritos y decidir, en primer instancia, cuáles deben continuar el proceso, de acuerdo con el alcance de la publicación y sus requerimientos formales.

- Establecer, junto con el Comité Editorial, la política editorial de la revista.

- Velar por la calidad académica y científica de la revista.

- Asistir a las reuniones del Comité Particular de Editores de Revistas Científicas.

- Presidir y orientar el Comité Editorial y Comité Científico.

- Convocar una reunión anual con el Comité Científico para actualizar información requerida por los SIRES.

- Velar por el cumplimiento del Reglamento Editorial de la Universidad Santo Tomás.

- Establecer un diálogo permanente con Ediciones USTA para garantizar el normal desarrollo de los procesos de edición.

- Coordinar el ingreso de la revista en los sistemas de indexación y resumen (SIR).

- Velar por el cumplimiento de los derechos de autor .

- Velar por la originalidad de los artículos, y verificar la misma mediante el software antiplagio.

- Coordinar el manejo del software Open Journal System.

- Sugerir pares evaluadores para los artículos, garantizar la transparencia en el dictamen de los evaluadores.

- Publicar en otras revistas (indexadas internacionalmente) artículos relacionados con las temáticas de la revista que dirige.

- Mantener un diálogo permanente con la Unidad de Investigación y la Editorial de la Universidad Santo Tomás para promover distintas actividades que puedan fortalecer la edición académica.

Por otra parte, es necesario que cada editor cuente con un asistente editorial, para que en otro medio tiempo apoye los procesos de la revista, para lograr que dichas publicaciones tengan realmente un impacto en el mundo académico. En este sentido, el cargo que se describe a continuación es necesario, dada la magnitud de datos que se debe incorporar a cada uno de los sistemas de indexación en los que se encuentre alojada la revista y la administración de la información que circula entre pares evaluadores-autores-comité editorial y científico- editor- Ediciones USTA- Unidad de Investigación.

El Asistente Editorial será delegado por el Editor de la revista y puede tener un perfil técnico; tendrá a su cargo las siguientes funciones:

- Ingresar la información de la revista en los sistemas de indexación a que haya lugar.

- Mantener actualizada la plataforma Open Journal System de la revista. 
- Llevar las actas de las diferentes reuniones del Comité Editorial y Comité Científico.

- Velar por el cumplimiento de las pautas para la presentación de artículos a la revista.

- Apoyar las funciones del Editor.

- Crear bases de datos de autores, evaluadores, futuros miembros del comité científico y sistemas de indexación.

- Tramitar el envío de ejemplares a los autores, miembros de comités, sistemas de indexación.

\section{FUENTES PARA EL DOCUMENTO}

La información planteada en este documento sobre políticas y calidad de una revista científica fue consultada en los siguientes enlaces:

http://scienti.colciencias.gov.co:8084/publindex/docs/informacionCompleta.pdf http://bvs.sld.cu/revistas/aci/vol9 s 01/sci23100.htm http://www.elsevier.com/online-tools/scopus/content-overview\#content-policy-and-sele ction 